\title{
Extreme Climate and Absence from Work: Evidence from Jamaica
}

\author{
Nekeisha Spencer $^{1} \cdot$ Mikhail-Ann Urquhart $^{1}$
}

Accepted: 23 December 2020/Published online: 27 January 2021

(C) The Author(s) 2021

\begin{abstract}
This study investigated the impact of extreme climate events on work absence in Jamaica. To this end, we constructed a quarterly individual level dataset on labor market and climatic data for 2004-2014. We find that while excess rainfall increases the odds of being temporarily absent from work, heat is unlikely to have an effect. The estimated outcome of excess rainfall is reasonable given the possibility of flooded roads, which can impede travel to work. This draws attention to the development of e-commuting policies to mitigate any negative effects on productivity.
\end{abstract}

Keywords Excess rainfall $\cdot$ Heat $\cdot$ Jamaica $\cdot$ Worker absence

\section{Introduction}

Jamaica is vulnerable to extreme climate events. In fact, based on an environmental vulnerability index that incorporates factors such as exposure to natural hazards and disasters and climate change, it is categorized as one of the most extremely vulnerable countries in the Caribbean (Kaly et al. 1999). This vulnerability is expected to increase in the future given projections in changing magnitudes and frequencies of climatic events. Climate extremes such as excess rainfall, which is often linked to hurricanes, have played a role in keeping employees stranded at home (Bureau of Labor Statistics 2012) due to

Nekeisha Spencer

nekeisha.spencer02@uwimona.edu.jm

1 Department of Economics, University of the West Indies, Kingston, Jamaica damaged roads and hazardous working conditions (Delp et al. 2009). Given Jamaica's vulnerability to these climate extremes, there are likely impacts on absences from work in the local labor market. Although there is no evidence to indicate that heat affects work absences in Jamaica, perhaps due to its relatively stable temperature patterns, the literature indicates that it may be an important consideration. For example, Zander and Matthew (2019) find that heat stress compromises economic activity due to a significant reduction in workers' productivity. ${ }^{1}$ The impact of climate extremes on work absence is therefore an important issue to investigate for Jamaica since there will be implications for economic growth and household welfare (Karim and Noy 2014; Henry et al. 2020).

There are several studies investigating the impact of extreme climate events on labor market outcomes. ${ }^{2}$ However, the literature is very limited in investigating the impact of extreme climate events, specifically, on absences from work. The existing studies on work absences, Coleman and Schaefer (1990) and Zander et al. (2015), focus only on temperature. In these studies, there appears to be no consensus on the directional impact of temperature since these studies point to either lower (Coleman and Schaefer 1990) or higher temperatures (Zander et al. 2015) increasing work absences. Further, the countries in these studies experience considerable variation in temperature, which would reasonably impact work absences while Jamaica on the other hand, may not observe significant effects due to the lack of wide variation in temperatures.

\footnotetext{
${ }^{1}$ The work of Somanathan et al. (2015), Zander et al. (2015), and Yi and Chan (2017) also indicate that heat stress can impact productivity.

2 These include Belasen and Polachek (2008) and Pecha Garzón (2017) on hurricanes, employment, and earnings and Graff Zivin and Neidell (2014) on temperature and hours worked.
} 
The lack of consensus in the small extreme climate-work absence literature, its narrow climate focus, and its likely inapplicability to Jamaica calls for further investigation as to how extreme climate events affect absence from work.

This study quantified the impact that extreme climate had on being temporarily absent from work in Jamaica. Research like this is important given the seemingly limited capacity of the Jamaican labor market to deal with work absenteeism and the daunting climate change projections that could affect the workforce. Further, this study provided a useful contribution to the extreme climate and work absenteeism literature in two main ways. First, it introduced a quantitative study in the Caribbean, a disasterprone region whose climatic future is marked by more intense and frequent weather events (Elsner et al. 2008; Burgess et al. 2018). Second, it made use of quarterly individual-level data, which is quite important in capturing the effects of climate extremes on worker absence. Third, it studied another extreme event, namely, excess rainfall, while the current literature presents only temperature.

The remainder of the article is organized as follows. In the next section we discuss the survey and climatic data along with the descriptive statistics. Section 3 follows with the results and discussion. Section 4 concludes with policy implications.

\section{Data and Descriptive Statistics}

To investigate the impact of extreme climate events on temporary absence from work, we used weather data and survey data on reported work absences and other labor market data as control variables.

\subsection{Individual-Level Data}

We used the Labour Force Survey of Jamaica, which is administered by the Statistical Institute of Jamaica. Due to data constraints, we only used 2004-2014 even though the survey started data collection in 1974. The survey collects quarterly data on the activities of individuals, 14 years of age or older, that are both in and outside of the labor force. A special feature of the survey is that it is constructed based on a rotating panel, which enables the construction of a panel of individuals. In terms of the panel structure, some individuals in the panel are interviewed ${ }^{3}$ for two consecutive periods and are then used again the subsequent year, while half of the panel are used between successive

\footnotetext{
3 A notable limitation is that we are unable to identify the exact date of interview. Thus, we do not know if an extreme event took place during the time period of the interview. This can possibly induce measurement error in disentangling the effect of extreme climate events on absence from work.
}

surveys. This structure allows for a panel construction enabling both annual and quarterly comparisons.

The survey provides data on key variables that are fundamental to the objective of this study where the focus is on employed individuals. The survey asks respondents whether they were temporarily absent from work and the reasons why, where one primary reason given is bad weather. This allows us to create two binary variables, namely, general absence from work and absence from work that captures individuals who reported not going to work due to bad weather. Further, the survey also asks respondents why they worked less hours per week where one reason given is bad weather. This allows us to supplement the analysis of temporary work absences due to bad weather. The survey also collects data on many variables that can serve as useful controls in the analysis. These are: years of schooling, age, job tenure, work sector, occupation type, employer or company size, location or place of work, and type of employment. The details of these controls are featured in Table 1.

\subsection{Climate Variables}

We used high resolution $(0.5 \times 0.5$ degree grids of global land areas) quarterly average measure of heat, measured in Celsius and rainfall, measured in millimeters as control variables. The source of these data is the Tropical Rainfall Measuring Mission (TRMM) satellite derived database. In addition, excess rainfall was constructed using the number of rainfall days that fall above the 90th percentile threshold as indicated by local weather stations.

\subsection{Descriptive Statistics}

Table 1 provides descriptive statistics for all variables. On average, approximately $2 \%$ of employed people reported being absent from work while $0.1 \%$ and $0.5 \%$ reported absence and working less hours due to bad weather respectively. Thus, there is a higher number of individuals reporting that they work less hours $(0.5 \%)$ than those reporting temporary absence $(0.1 \%)$ due to bad weather. The average quarterly values for rainfall, excess rainfall, and heat respectively are $4.8 \mathrm{~mm}, 5.2$ days, and $26.9{ }^{\circ} \mathrm{C}$. The average age of the sample is 41 years and years of schooling averages around 10 years.

As it relates to job tenure, $68.7 \%$ of the sample worked for five years or more. However, there is a big disparity between those working at least five years and those working for less than five years. As the table shows, roughly $15 \%$ of employees have between 2 - and 5-years tenure at their current jobs. The smallest percentage $(1.7 \%)$ tenure is for less than one year but in excess of nine months. The majority of the sample reported being 
Table 1 Descriptive statistics

\begin{tabular}{|c|c|c|}
\hline Variables & Mean & SD \\
\hline \multicolumn{3}{|l|}{ Dependent } \\
\hline Temporary absence & 0.019 & 0.137 \\
\hline Temporary absence due to bad weather & 0.001 & 0.025 \\
\hline Work less hours due to bad weather & 0.005 & 0.071 \\
\hline \multicolumn{3}{|l|}{ Other weather } \\
\hline Extreme rainfall & 5.178 & 4.303 \\
\hline Rainfall & 4.822 & 3.218 \\
\hline Heat & 26.868 & 1.825 \\
\hline \multicolumn{3}{|l|}{ Other controls } \\
\hline Age & 41.131 & 13.802 \\
\hline Age-squared & 1882.303 & 1251.875 \\
\hline Years of schooling & 9.992 & 2.460 \\
\hline \multicolumn{3}{|l|}{ Job tenure dummies } \\
\hline Less than 3 months & 0.032 & 0.176 \\
\hline 3 months but less than 6 months & 0.029 & 0.167 \\
\hline 6 months but less than 9 months & 0.024 & 0.152 \\
\hline 9 months but less than 12 months & 0.017 & 0.129 \\
\hline 1 year but less than 2 years & 0.065 & 0.247 \\
\hline 2 years but less than 5 years & 0.147 & 0.354 \\
\hline 5 or more years & 0.687 & 0.464 \\
\hline \multicolumn{3}{|l|}{ Sector } \\
\hline Employee of central or local government & 0.095 & 0.294 \\
\hline Employee of other government agencies & 0.030 & 0.170 \\
\hline Employee of private sector & 0.458 & 0.498 \\
\hline Unpaid family worker & 0.013 & 0.115 \\
\hline Employer & 0.029 & 0.168 \\
\hline Own account worker & 0.372 & 0.483 \\
\hline Not given & 0.002 & 0.043 \\
\hline \multicolumn{3}{|l|}{ Employment by industry } \\
\hline Agriculture & 0.002 & 0.047 \\
\hline Mining & 0.063 & 0.242 \\
\hline Manufacturing & 0.068 & 0.251 \\
\hline Electricity & 0.055 & 0.228 \\
\hline Construction and installation & 0.084 & 0.278 \\
\hline Wholesale and retail & 0.188 & 0.391 \\
\hline Transport and storage & 0.194 & 0.395 \\
\hline Financing and insurance & 0.140 & 0.347 \\
\hline Community and social services & 0.060 & 0.238 \\
\hline Industry not stated & 0.146 & 0.354 \\
\hline \multicolumn{3}{|l|}{ Employer size } \\
\hline 1 person & 0.451 & 0.498 \\
\hline $2-4$ persons & 0.161 & 0.368 \\
\hline 5-9 persons & 0.084 & 0.277 \\
\hline $10-49$ persons & 0.170 & 0.375 \\
\hline $50+$ persons & 0.135 & 0.342 \\
\hline \multicolumn{3}{|l|}{ Workplace } \\
\hline Home & 0.053 & 0.223 \\
\hline Farm & 0.187 & 0.390 \\
\hline
\end{tabular}

Table 1 continued

\begin{tabular}{lll}
\hline Variables & Mean & SD \\
\hline Employer's house & 0.061 & 0.240 \\
Construction site & 0.066 & 0.248 \\
Factory & 0.343 & 0.475 \\
Street (fixed location) & 0.030 & 0.170 \\
Street (no fixed location) & 0.052 & 0.223 \\
Shop & 0.138 & 0.345 \\
Market & 0.026 & 0.158 \\
Other location & 0.044 & 0.205 \\
Employment type & & \\
Public & 0.125 & 0.331 \\
Self & 0.402 & 0.490 \\
Private & 0.473 & 0.499 \\
Observations & 23,928 & \\
\hline
\end{tabular}

employees of private sector companies (46\%) and being an own account worker (37\%). Place of work appears to vary significantly among respondents. Most (34\%) respondents reported their workplace being at a factory, $19 \%$ being at a farm, and $14 \%$ being at a shop. The remaining places of work including at construction site, the market, employer's house, and home each totaled below $7 \%$. Finally, the majority $(47 \%)$ of the respondents belong to the private sector, followed by self-employed $(40 \%)$ and the public sector $(13 \%)$.

\section{Results and Discussion}

This section describes the econometric model used to estimate the impact of extreme climate on temporary work absence. We also discuss our results in a number of parts. First, we discuss the results for employees who reported absence from work for any reason and the interaction effects from this sample. Second, we discuss the results for employees who reported work absence specifically due to bad weather along with the interaction effects of this subsample. Third, we discuss our exploration of lagged climatic effects. Fourth, we discuss the results from examining those employees who reported working less hours due to bad weather. Finally, we discuss the limitations of our analysis.

\subsection{Econometric Model}

To estimate the impact of extreme weather on being temporarily absent from work, we used the following benchmark model and applied conditional fixed effects logistic regressions. 


$$
\begin{aligned}
T A_{i j t}= & \propto_{1}+\propto_{2} \sum_{l=0}^{1} X_{i j t-l}+\propto_{3} W_{i j t-l}+\propto_{5} C_{i j t}+y_{y}+q_{d} \\
& +p_{d}+\gamma_{i}+\varepsilon_{i j t}
\end{aligned}
$$

$T A_{i j t}$ is the temporary work absence binary variable for individual $i$ in district $j$ at time $t .{ }^{4} X_{i j t}$ is excess rainfall. $W_{i j t}$ is a vector containing rainfall and heat. $l$ captures the lagged weather variables, where $l$ goes from $t=0$ to $t=1$. $C$ is a vector containing years of schooling, age, agesquared, and the following dummy variables: job tenure, work sector, occupation type, employer or company size, location or place of work, and type of employment. $y_{y}, q_{d}$, and $p_{d}$ are year, quarter, and parish fixed effects while $\gamma_{i}$ captures individual specific unobservables that can possibly be correlated with other explanatory variables. $\varepsilon_{i j t}$ is the error term and are clustered at the individual level.

\subsection{Temporary Absence from Work}

The impact of excess rainfall on being absent from work is first estimated without controlling for individual specific fixed effects, $\gamma$. The second column of Table 2 shows the estimated odd ratios. As can be seen, there is no impact of excess rainfall on being temporarily absent from work. This is also true for heat and rainfall. As shown in column 3 , estimating the impact of extreme climate with fixed effects produces the same outcome but with slight changes in the odd ratios. Thus, controlling for time invariant individual specific fixed effects can influence the magnitude of the estimated outcomes and as a result, this is the preferred model that is used for the remaining discussion since it reduces biasedness of our estimates. Overall, the results show that extreme climate do not affect the odds of employees' temporary absence compared to a case of no extreme climate. This no-climate impact has been noted in the works of Pecha Garzón (2017) on Jamaica with hurricanes (linked with excess rainfall) and Belasen and Polachek (2008) on Florida with hurricanes where they focused on indicators such as wages and employment. Additionally, Wilson (2017) indicates that economies become less sensitive to climate conditions with which they are familiar, such as heat.

Table 3 shows the interaction effects of excess rainfall with workplace and employment type. As Model 1 shows, there is no overall impact of excess rainfall on odds of an employee being temporarily absent. However, in terms of employment industry, we note that excess rainfall increases the odds of being absent for those working in a shop, at home, in a market, or on a farm and is at least 1.075 higher

\footnotetext{
$\overline{4 \text { Time } t \text { goes }}$ from 2004 quarter 1 to 2014 quarter 4 .
}

Table 2 The impact of extreme climate on temporary work absence

\begin{tabular}{lll}
\hline Variables & $(1)$-Pooled & $(2)$-Fixed effects \\
\hline Excess rainfall & 1.012 & 1.006 \\
\multirow{2}{*}{ Rainfall } & $(0.010)$ & $(0.013)$ \\
& 1.001 & 1.014 \\
Heat & $(0.018)$ & $(0.021)$ \\
& 0.987 & 0.965 \\
Observations & $(0.013)$ & $(0.041)$ \\
\hline
\end{tabular}

(i) Models 1 and 2 present the odd ratios and include all the controls listed in Table 1

(ii) The dependent variable is temporary absence from work where temporary absence is 1,0 otherwise

(iii) Standard errors in parentheses

${ }^{\text {a }}$ The observations were reduced to 15,504 owing to the lack of variability where individuals reported either absence from work or no absence from work. For those individuals that remained in the analysis, their status varied from absence to not being absent or vice versa

than if there was no excess rain. The absences for shop, market, and farm can possibly be attributed to road conditions (Miller et al. 2009), which makes it difficult to get to work or the lack of public transportation given its vulnerability to weather (Leviäkangas et al. 2011; Kaufman et al. 2012). This is supported by local evidence where heavy rainfall makes it difficult for people to travel (Jamaica Observer 2019; The Gleaner 2019) and bus services have been temporarily suspended due to impassable roads from debris. Thus, it is easy to appreciate that excess rainfall can drive worker absences (Jamaica Observer 2017). Unexpectedly, is the increasing absence for those working at home. A plausible explanation is prevention of other household members from leaving home due to excess rain resulting in distractions (Srivastava et al. 2015), thus rendering an at-home worker incapable of carrying out work responsibilities. Interestingly, excess rainfall reduces the odds of a factory worker being absent from work, which can possibly be explained by factory employers providing transportation or workers living in close proximity to work or they are able to work from home, in which case they are less likely to report absence from work. Overall, we see that the odds are higher for farm and market workers being absent compared to those working from home or in a shop but only marginally, that is, between 0.003 and 0.03 . Perhaps, the location of where the work is carried out is a factor, where for example, farm and market workers may have to travel further and would therefore be constrained by rainfall impacts.

Turning our attention to Model 2, where public and private sector workers are added, we see that excess 
Table 3 The impact of extreme climate on temporary work absence: interaction effects

\begin{tabular}{|c|c|c|}
\hline Variables & (1) & (2) \\
\hline Excess rainfall & $\begin{array}{l}1.017 \\
(0.021)\end{array}$ & $\begin{array}{l}1.034 * \\
(0.021)\end{array}$ \\
\hline Rainfall & $\begin{array}{l}0.993 \\
(0.021)\end{array}$ & $\begin{array}{l}1.000 \\
(0.021)\end{array}$ \\
\hline Heat & $\begin{array}{l}0.958 \\
(0.041)\end{array}$ & $\begin{array}{l}0.947 \\
(0.041)\end{array}$ \\
\hline \multicolumn{3}{|c|}{ Interaction: Workplace_"type"*ExcessRainfall } \\
\hline _Home*ExcessRainfall & $\begin{array}{l}1.075^{* *} \\
(0.028)\end{array}$ & $\begin{array}{l}1.069 * * \\
(0.031)\end{array}$ \\
\hline _Farm*ExcessRainfall & $\begin{array}{l}1.101 * * * \\
(0.029)\end{array}$ & $\begin{array}{l}1.094 * * * \\
(0.031)\end{array}$ \\
\hline _EmployersHouse*ExcessRainfall & $\begin{array}{l}1.051 \\
(0.035)\end{array}$ & $\begin{array}{l}1.035 \\
(0.033)\end{array}$ \\
\hline _Factory*ExcessRainfall & $\begin{array}{l}0.956^{* *} \\
(0.017)\end{array}$ & $\begin{array}{l}0.978 \\
(0.018)\end{array}$ \\
\hline _Street-Fixed*ExcessRainfall & $\begin{array}{l}1.043 \\
(0.039)\end{array}$ & $\begin{array}{l}1.038 \\
(0.041)\end{array}$ \\
\hline _Street-NotFixed*ExcessRainfall & $\begin{array}{l}1.031 \\
(0.035)\end{array}$ & $\begin{array}{l}1.028 \\
(0.036)\end{array}$ \\
\hline _Shop*ExcessRainfall & $\begin{array}{l}1.089 * * * \\
(0.028)\end{array}$ & $\begin{array}{l}1.073 * * \\
(0.028)\end{array}$ \\
\hline _Market*ExcessRainfall & $\begin{array}{l}1.092 * \\
(0.053)\end{array}$ & $\begin{array}{l}1.085 \\
(0.055)\end{array}$ \\
\hline \multicolumn{3}{|c|}{ Interaction: Employment_"type”*ExcessRainfall } \\
\hline _Public*ExcessRainfall & & $\begin{array}{l}0.903 * * * \\
(0.0146)\end{array}$ \\
\hline _Self*ExcessRainfall & & $\begin{array}{l}0.982 \\
(0.019)\end{array}$ \\
\hline Observations & 15,504 & 15,504 \\
\hline
\end{tabular}

(i) Models 1 and 2 present the odd ratios and include all the controls listed in Table 1

(ii) The dependent variable is temporary absence from work where temporary absence is 1,0 otherwise

(iii) Standard errors in parentheses

(iv) $* * * p<0.01 ; * * p<0.05 ; * p<0.1$

rainfall increases the odds of being absent by 1.034 . The directional impact for home, farm, factory, and market workers remain the same except for the insignificance that is now noted for factory and market. Note also that compared to a private sector worker, the odds of an individual working in the public sector being absent from work is 0.9 lower than being absent if there is no excess rainfall.

\subsection{Temporary Absence from Work Due to Weather}

Those who reported, in general, to be temporarily absent from work does not necessarily allow one to infer the reason for such absence. As such, in Table 4 we show the results of using only those individuals who reported being absent from work due to bad weather. The table reveals that controlling for individual specific fixed effects does make a difference in the overall significance of the estimates, especially with regards to rainfall. The odd ratios of Model 2 indicate that extreme weather has an impact on temporary work absence. One can see that excess rainfall significantly increases the odds of being temporarily absent from work. In other words, the odds of temporary absence due to excess rainfall is 1.283 higher compared to the situation in which there was no extremity in rainfall levels. Understandably, the usual rainfall levels decrease the odds of employees being absent by 0.680 . One may want to note that climate extremes can possibly impact work absence through impassable roads (Spencer et al. 2016), disruption in the transportation system (Kaufman et al. 2012), and general safety concerns (Delp et al. 2009; Leviäkangas et al. 2011). In this regard, the results are limited in the sense of not being able to identify the specific channel through which a worker's absence is impacted due to climate extremes. Note also that heat does not affect worker absence, which is expected since Jamaica has relatively stable temperature conditions.

Table 5 extends Model 2 in Table 4 by including interaction effects of excess rainfall with employment type and place of work. Model 1, which shows climate interactions with workplace reveals that regardless of one's place of employment, excess rainfall do not significantly affect the odds of temporary absence. On the other hand, Model 2, which adds interactions with type of employment, produces different results. First, we note that in general, excess rainfall increases the odds of temporary absence but like Model 1, usual rainfall decreases the odds of worker absence. Of course, the higher likelihood of absence due to excess rainfall implies associated flooding, which impacts movement and travel to work. Conversely, normal rainfall would generally not cause major disruptions and so it is understandable why workers are less likely to be temporarily absent. Second, the odds of being absent are greater for factory worker (1.36) than for a farm worker (1.22). Third, compared to a private sector worker, there is no impact on the odds of an individual working in the public sector being temporarily absent from work due to excess rainfall; an outcome that can be explained by employers having mechanisms in place to reduce absence such as through transportation and work-from-home infrastructure. 
Table 4 The impact of extreme climate on temporary work absence due to bad weather

\begin{tabular}{lll}
\hline Variables & $(1)$ _Pooled & $(2)$ _Fixed effects \\
\hline Excess rainfall & 1.075 & $1.283^{* * *}$ \\
& $(0.0735)$ & $(0.122)$ \\
Rainfall & 0.847 & $0.680^{* * *}$ \\
& $(0.088)$ & $(0.098)$ \\
Heat & 1.102 & 1.143 \\
& $(0.101)$ & $(0.348)$ \\
Observations & 7,465 & 614 \\
\hline
\end{tabular}

(i) Models 1 and 2 present the odd ratios and include all the controls listed in Table 1

(ii) The dependent variable captures individuals who reported temporary absence from work due to bad weather where temporary absence is 1,0 otherwise

(iii) Standard errors in parentheses

(iv) $* * * p<0.01$

\subsection{Temporary Absence from Work: Lagged Climate Effects}

We next investigate whether extreme climate conditions have any persistent impact as many in the weather literature have done (Spencer and Polachek 2015; Spencer and Urquhart 2018; Henry et al. 2020). These results are shown in Table 6. Model 1 presents the results for all workers who reported being absent from work. Here we note the insignificance of the one period excess rainfall lag. ${ }^{5}$ Model 2 shows the results for workers who reported being absent specifically due to bad weather. Again, we obtain the same outcome for excess rainfall and rainfall. Although unknown, one may want to note that it may be possible that employees reported climate-related work absence but could be facing circumstances related to excess rainfall such as family and health issues or could just be using bad weather as an opportunity to avoid work obligations (Shi and Skuterud 2015; Žikić and Rabi-Žikić 2018). We also find no impact on the odds of being absent one quarter after the experience with excess rainfall. This demonstrates that the experience of excess rainfall has possibly strengthened the labor market to mitigate against such shocks beyond current time period perhaps through e-commuting or workers being able to successfully deal with effects of excess rain.

\footnotetext{
5 Model specification choice of a one period lag is based on robustness. Lags beyond the first period are insignificant to the analysis.
}

Table 5 The impact of extreme climate on temporary work absence due to bad weather: Interaction effects

\begin{tabular}{|c|c|c|}
\hline Variables & (1) & (2) \\
\hline Excess rainfall & $\begin{array}{l}1.179 \\
(0.129)\end{array}$ & $\begin{array}{l}1.243^{*} \\
(0.148)\end{array}$ \\
\hline Rainfall & $\begin{array}{l}0.689 * * \\
(0.402)\end{array}$ & $\begin{array}{l}0.679 * * \\
(0.104)\end{array}$ \\
\hline Heat & $\begin{array}{l}1.250 \\
(0.402)\end{array}$ & $\begin{array}{l}1.223 \\
(0.397)\end{array}$ \\
\hline \multicolumn{3}{|c|}{ Interaction: Workplace_"type”*ExcessRainfall } \\
\hline _Home*ExcessRainfall & $\begin{array}{l}1.121 \\
(0.183)\end{array}$ & $\begin{array}{l}1.128 \\
(0.205)\end{array}$ \\
\hline _Farm*ExcessRainfall & $\begin{array}{l}1.150 \\
(0.107)\end{array}$ & $\begin{array}{l}1.221^{*} \\
(0.139)\end{array}$ \\
\hline _EmployersHouse*ExcessRainfall & $\begin{array}{l}1.666 \\
(1.137)\end{array}$ & $\begin{array}{l}1.512 \\
(1.026)\end{array}$ \\
\hline _Factory*ExcessRainfall & $\begin{array}{l}1.288 \\
(0.222)\end{array}$ & $\begin{array}{l}1.361 * \\
(0.237)\end{array}$ \\
\hline _Street-Fixed*ExcessRainfall & $\begin{array}{l}0.634 \\
(0.357)\end{array}$ & $\begin{array}{l}0.665 \\
(0.385)\end{array}$ \\
\hline _Street-NotFixed*ExcessRainfall & $\begin{array}{l}1.152 \\
(0.190)\end{array}$ & $\begin{array}{l}1.216 \\
(0.219)\end{array}$ \\
\hline _Shop*ExcessRainfall & $\begin{array}{l}0.245 \\
(0.259)\end{array}$ & $\begin{array}{l}0.261 \\
(0.269)\end{array}$ \\
\hline _Market*ExcessRainfall & $\begin{array}{l}1.116 \\
(0.177)\end{array}$ & $\begin{array}{l}1.198 \\
(0.212)\end{array}$ \\
\hline \multicolumn{3}{|c|}{ Interaction: Employment_"type"*ExcessRainfall } \\
\hline _Public*ExcessRainfall & & $\begin{array}{l}0.708 \\
(0.179)\end{array}$ \\
\hline _Self*ExcessRainfall & & $\begin{array}{l}0.896 \\
(0.092)\end{array}$ \\
\hline Observations & 614 & 614 \\
\hline
\end{tabular}

(i) Models 1 and 2 present the odd ratios and include all the controls listed in Table 1

(ii) The dependent variable captures individuals who reported temporary absence from work due to bad weather where temporary absence is 1,0 otherwise

(iii) Standard errors in parentheses

(iv) $* * * p<0.01$; **p $<0.05$; * $p<0.1$

\subsection{Temporary Absence from Work: Working Less Hours Due to Bad Weather}

Another alternative to using the variable that captures workers' temporary absence is to examine those who reported working less than 32 hours due to bad weather. Table 7, which displays these results, corroborates the general evidence of excess rainfall having a contemporaneous labor market impact and the non-existence of an effect one period after the event. Perhaps the latter outcome 
Table 6 The impact of extreme climate on temporary work absence and absence due to bad weather: Lagged weather effects

\begin{tabular}{lll}
\hline Variables & $(1)$ & $(2)$ \\
\hline Excess rainfall & 1.011 & $1.300^{* * *}$ \\
& $(0.013)$ & $(0.132)$ \\
Rainfall & 1.009 & $0.689 * *$ \\
& $(0.022)$ & $(0.107)$ \\
Heat & 0.993 & 1.078 \\
& $(0.044)$ & $(0.346)$ \\
Lag 1_ExcessRainfall & 1.004 & 0.946 \\
& $(0.006)$ & $(0.042)$ \\
Observations & 14,248 & 560 \\
\hline
\end{tabular}

(i) Models 1 and 2 include all the controls listed in Table 1

(ii) The dependent variable captures individuals who reported temporary absence from work where temporary absence is 1,0 otherwise for Model 1; captures individuals who reported temporary absence from work due to bad weather where temporary absence due to bad weather is 1,0 otherwise for Model 2

(iii) Standard errors in parentheses

(iv) $* * * p<0.01 ; * * p<0.05$

Table 7 The impact of extreme climate on working less hours due to bad weather

\begin{tabular}{lll}
\hline Variables & $(1)$ & $(2)$ \\
\hline Excess rainfall & $1.282^{* * *}$ & $1.325^{* * *}$ \\
& $(0.104)$ & $(0.116)$ \\
Rainfall & $0.739^{* *}$ & $0.726^{* *}$ \\
& $(0.089)$ & $(0.092)$ \\
Heat & 0.887 & 1.126 \\
& $(0.227)$ & $(0.316)$ \\
Lag 1_ExcessRainfall & & 0.968 \\
& & $(0.034)$ \\
Observations & 736 & 670 \\
\hline
\end{tabular}

(i) Models 1 and 2 include all the controls listed in Table 1

(ii) The dependent variable captures individuals who reported working less hours due to bad weather where working less hours is 1,0 otherwise for Model 1

(iii) Standard errors in parentheses

(iv) $* * * p<0.01 ; * * p<0.05$

can be explained by employees working from home; thus, they take account of the fact that they are still working and are counting hours. We also note that there are similar results for rainfall and heat in previous models where the former reduces the odds of absence and the latter has no effect on the odds of being absent. Once again, a no-heat effect is expected given the stability in Jamaica's temperature.

\subsection{Study Limitations}

There are some limitations that are important to mention, which if considered can strengthen estimated outcomes especially when using survey data. First, the survey does not collect data on the health of employees, which could be important since work absence can be impacted by health. Second, it is not possible to identify the exact mechanisms (including impassable roads and workplace closure) through which absence is impacted due to bad weather. Third, there is no clear definition of bad weather in the survey. Fourth, there is no information on whether employers can facilitate work-from-home in times of extreme climate events. Thus, future surveys can be refined to capture these data.

\section{Conclusion and Policy Implications}

This study investigated the impact that extreme climate has on absence from work. The estimations show that excess rainfall does impact temporary absence from work depending on the place and type of employment. Possible reasons for increased likelihood of absence include poor road conditions and disruption in public transportation systems. On the other hand, a lower likelihood of absence can be attributed to employers having in place arrangements for work to be carried out from home or other locations. Further, we consistently find that heat has no effect on the odds of being temporarily absent from work, an outcome that can be attributed to Jamaica's relatively stable temperature patterns and as such, is not considered as an extreme weather event in this study.

The outcome of this study has implications for the Jamaican labor market adapting to the effects of excess rainfall, an extreme event that is common locally and has been known to cause landslides and unsafe roads. Further, the climate change literature indicates that excess rainfall is quite possible in the future. Since Jamaica is vulnerable to climate change events, it means that worker absence can become a serious issue in the future. Thus, one may expect an increase in climate-related work absence, which may have implications for productivity and economic growth. The local labor market, therefore, should focus on mitigating the impact that excess rainfall has on absence from work perhaps by instituting e-commuting policies where employees can work from home or from other locations if the home environment is not conducive to work. In addition, the labor market can help employees adapt to changing situations, perhaps through training sessions so that productivity is not impacted. Where such policies are deemed inappropriate, employers need to arrange for 
employees whose work has to take place on the work site to be present.

Acknowledgements This article is based on research done for the International Labour Organization on labor market and resilience in the Caribbean.

Open Access This article is licensed under a Creative Commons Attribution 4.0 International License, which permits use, sharing, adaptation, distribution and reproduction in any medium or format, as long as you give appropriate credit to the original author(s) and the source, provide a link to the Creative Commons licence, and indicate if changes were made. The images or other third party material in this article are included in the article's Creative Commons licence, unless indicated otherwise in a credit line to the material. If material is not included in the article's Creative Commons licence and your intended use is not permitted by statutory regulation or exceeds the permitted use, you will need to obtain permission directly from the copyright holder. To view a copy of this licence, visit http://creativecommons. org/licenses/by/4.0/.

\section{References}

Belasen, A.R., and S.W. Polachek. 2008. How hurricanes affect wages and employment in local labor markets. American Economic Review 98(2): 49-53.

Bureau of Labor Statistics. 2012. Work absences due to bad weather: Analysis of data from 1977 to 2010. Issues in Labor Statistics, U.S. Bureau of Labor Statistics, Summary 12-1/February 2012. Washington, DC, USA.

Burgess, C.P., M.A. Taylor, N. Spencer, J. Jones, and T.S. Stephenson. 2018. Estimating damages from climate-related natural disasters for the Caribbean at $1.5^{\circ} \mathrm{C}$ and $2{ }^{\circ} \mathrm{C}$ global warming above preindustrial levels. Regional Environmental Change 18(8): 2297-2312.

Coleman, D.F., and N.V. Schaefer. 1990. Weather and absenteeism. Canadian Journal of Administrative Sciences 7(4): 35-42.

Delp, L., L. Podolsky, and T. Aguilar. 2009. Risk amid recovery: Occupational health and safety of Latino day laborers in the aftermath of the gulf coast hurricanes. Organization \& Environment 22(4): 479-490.

Elsner, J.B., J.P. Kossin, and T.H. Jagger. 2008. The increasing intensity of the strongest tropical cyclones. Nature 455(7209): 92-95.

Graff Zivin, J., and M. Neidell. 2014. Temperature and the allocation of time: Implications for climate change. Journal of Labor Economics 32(1): 1-26.

Henry, M., N. Spencer, and E. Strobl. 2020. The impact of tropical storms on households: Evidence from panel data on consumption. Oxford Bulletin of Economics and Statistics 82(1): 1-22.

Jamaica Observer. 2017. Flooding disrupts several activities; some places without water and electricity. http://www.jamaicaobser ver.com/news/flooding-disrupts-several-activities-some-placeswithout-water-and-electricity_99110?profile $=1373$. Accessed 10 Apr 2020.

Jamaica Observer. 2019. Processing of farm workers unable to reach labour ministry today will be rescheduled. http://www.jamai caobserver.com/latestnews/Processing_of_farm_workers_ unable_to_reach_labour_ministry_today_will_be_rescheduled? profile $=1228 \&$ template $=$ MobileArticle. Accessed 10 May 2020 .
Kaly, U., L. Briguglio, H. McLeod, S. Schmall, C. Pratt, and R. Pal. 1999. Environmental Vulnerability Index (EVI) to summarise national environmental vulnerability profiles. SOPAC Technical Report No. 275. South Pacific Applied Geosciences Commission, Fiji.

Karim, A., and I. Noy. 2014. Poverty and natural disasters: A metaanalysis. School of Economics and Finance Working Paper No. 04/2014. Victoria University of Wellington, Wellington, New Zealand.

Kaufman, S.M., C. Qing, N. Levenson, and M. Hanson. 2012. Transportation during and after Hurricane Sandy. New York, USA: New York University.

Leviäkangas, P., A. Tuominen, R. Molarius, J. Schabel, S. Toivonen, J. Keränen, J. Törnqvist, and L. Makkonen et al. 2011. Extreme weather impacts on transport systems. Finland: VTT Technical Research Centre of Finland, VTT.

Miller, S., T. Brewer, and N. Harris. 2009. Rainfall thresholding and susceptibility assessment of rainfall-induced landslides: Application to landslide management in St Thomas, Jamaica. Bulletin of Engineering Geology and the Environment 68(4): 539-550.

Pecha Garzón, C.J. 2017. The effects of natural disasters on the labour market: Do hurricanes increase informality? IDB Working Paper No. IDB-WP-854. International Development Bank, Iraq.

Shi, J., and M. Skuterud. 2015. Gone fishing! Reported sickness absenteeism and the weather. Economic Inquiry 53(1): 388-405.

Somanathan, E., R. Somanathan, A. Sudarshan, and M. Tewari. 2015. The impact of temperature on productivity and labor supply: Evidence from Indian manufacturing. New Delhi, India: Indian Statistical Institute.

Spencer, N., and S. Polachek. 2015. Hurricane watch: Battening down the effects of the storm on local crop production. Ecological Economics 120: 234-240.

Spencer, N., and M.A. Urquhart. 2018. Hurricane strikes and migration: Evidence from storms in central America and the Caribbean. Weather, Climate, and Society 10(3): 569-577.

Spencer, N., S. Polachek, and E. Strobl. 2016. How do hurricanes impact scholastic achievement? A Caribbean perspective. Natural Hazards 84(2): 1437-1462.

Srivastava, K., A. Sethumadhavan, H. Raghupathy, S. Agarwal, and S.R. Rawat. 2015. To study the Indian perspective on the concept of work from home. Indian Journal of Science and Technology 8(S4): 212-220.

The Gleaner. 2019. More roads impacted by heavy rainfall-NWA. http://jamaica-gleaner.com/article/news/20190925/more-roadsimpacted-heavy-rainfall-nwa. Accessed 10 Apr 2020.

Wilson, D.J. 2017. The impact of weather on local employment: Using big data on small places. Federal Reserve Bank of San Francisco.

Yi, W., and A.P. Chan. 2017. Effects of heat stress on construction labor productivity in Hong Kong: A case study of rebar workers. International Journal of Environmental Research and Public Health 14(9). https://doi.org/10.3390/ijerph14091055.

Zander, K.K., and S. Mathew. 2019. Estimating economic losses from perceived heat stress in urban Malaysia. Ecological Economics 159: 84-90.

Zander, K.K., W.J. Botzen, E. Oppermann, T. Kjellstrom, and S.T. Garnett. 2015. Heat stress causes substantial labour productivity loss in Australia. Nature Climate Change 5(7): 647-651.

Žikić, M., and T. Rabi-Žikić. 2018. Meteoropathy and meteorosensitive persons. Medicinski Pregled 71(3-4): 131-135. 